\title{
Quality Examination Framework for Ethiopian Healthcare Websites
}

\author{
Lami Garoma Abaya, Selvakumar Subramanian
}

\begin{abstract}
Website becomes an important tool for organizations to put their product online. Similarly, health care organizations allow to serve their patients online as well as to deliver information. In Ethiopia, healthcare providers have websites even though the usages of the website by end-users are not become familiar due to their interpretation on the standard of the existing website. The objective of this study is to develop a website quality evaluation framework for Ethiopian healthcare organizations which is used as guidelines for developers of healthcare website in Ethiopia. To develop the framework an extensive literature study was done on quality models, design guidelines, accessibility guidelines to identify characteristics, sub-characteristics and quality indicators. The proposed framework (HWebQE) was tested on three Ethiopian healthcare providers' website as case study using questionnaire prepared from the quality indicators. The results of this study show that the overall qualities of the available Ethiopian healthcare provider's website are in the moderate quality level.
\end{abstract}

Keywords: Ethiopian Healthcare Website Evaluation, Health Website Quality Evaluation, Cronbach's alpha, Webuse.

\section{INTRODUCTION}

W ebsites has been used in different countries internationally which makes peoples can be access whatever they want at their home just by having computers and internet connections and the owner of the website to put their product or services online[1][2][3]. The previous study proved that the reliance of people increases from day to day on the website to online search information, shopping, communicating with people and performing different tasks[3][4]. To increase the confidence of the users, each owner of the website should provide what users are expected from the website and which in turn increase the usability of the website. Healthcare related websites are owned by healthcare providers [6]. The quality of a website can be addressed in different ways[8][5][9]. Those are developing the website based on international standards, accessibility guidelines, estimating what customer needs and evaluating the website with different target groups like the end-user, expert and managers[9][10][11].

Evaluation of the website used for identifying which part of the website needs improvement of quality and which part

Revised Manuscript Received on October 10, 2019.

* Correspondence Author

Lami Garoma Abaya, Department of Computer Science, Ambo University, Ambo, Ethiopia. Email: lami.garoma@ambou.edu.et

Selvakumar Subramanian*, Department of Computer Science and Engineering, GKM College of Engineering \& Technology, Chennai, India. Email: sselvakumar@yahoo.com

does not need. The concept of all previous work was similar, which all of them are working on the improvement of characteristics, sub-characteristics and quality metrics (quality indicators) [12][13][9][20]. Website evaluation framework evaluates the quality of website by identifying the requirements of the different perspectives of users those interact with the website while it is in the operational stage[2][4][22][25]. The framework identified and included relevant characteristics, sub-characteristics and quality indicators utilized to evaluate the quality of healthcare website on end user perspective. In addition to solving the problem of the website quality the research also addressed quality evaluation characteristics, sub-characteristics and criteria those are highly relevant to the healthcare website than other website domains. The rest of the paper is organized as following sections. Section II discusses the methods employed to solve the problem. Section III discusses the development of the HCWebQ framework. Section IV discusses the testing and validation of the HCWebQ framework. Section $\mathrm{V}$ provides a conclusion and recommendation for future work.

\section{METHODOLOGY}

The method used for HCWebQ framework testing, also elaborated along with the background theory which makes the method usable to evaluate the proposed HCWebQ framework. In the following section a brief discussion of the study, the design of the HCWebQ framework, sampling of participants, data collection, ethical consideration of participants, and testing and validation of the HCWebQ framework.

\section{A. Design of the HCWebQ evaluation framework}

The proposed HCWebQ was constructed from literature on website quality[32], literature on software quality evaluation[9][24][10][21], related works[2][12][17][11][33], website design guidelines, healthcare website design guidelines, uses of Ethiopian healthcare websites, website accessibility guidelines, software evaluation standards. The metrics are categorized under the sub-characteristics that they are aimed to evaluate on the page of the website. Related work in this research used to represent both health website quality evaluation frameworks and website quality evaluation frameworks. The general approach used in the research depicted in the Fig. 1. 


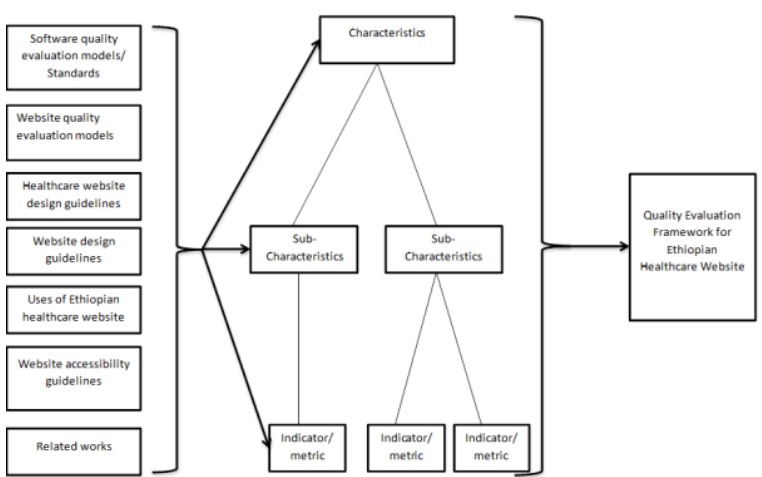

Fig. 1.Methodology for developing the HCWebQ framework

The developed framework for Ethiopian healthcare website quality evaluation was tested and validated using questionnaire. The questionnaire constructed from the metrics or indicators selected under sub-characteristics of a framework. Each question was designed to address quality metrics directly measured from the website page. Cronbach's alpha and item-total correlation were used to analyze the consistency of responses gathered from end-users. The questionnaire applied to Kadisco general hospital, St. Paul's hospital millennium medical college, Wudassie diagnostic center websites as case study and the result of questionnaire analyzed for testing and validations of the HCWebQ framework. Internal consistency of the questions in a questionnaire analyzed using statistical analysis method called Cronbach's alpha which is suitable for analyzing multiple Likert scale questionnaire used for data collection [34]. Cronbach's alpha used to measure the reliability (internal consistency) of the questions (items) in the questionnaire. Items in a questionnaire are reliable means it is possible to analyze the data collected by the items or questions and can be possible to interpret the data. The Cronbach's alpha is given as[34].

$$
\alpha=\frac{N \cdot \bar{c}}{\bar{v}+(N-1) \cdot \bar{c}}
$$

Where $\mathrm{N}$ is the number of items, $\overline{\mathrm{c}}$ is average covariance and $\overline{\mathrm{v}}$ is average variance.

The value of Cronbach's alpha, starts from 0 and up to 1[2]. After data collected using question prepared in the questionnaire then interpretation given for Cronbach's alpha are as a follow[2][35][34]:

WEBUSE analysis calculated from the data collected and the final result of high-level characteristics in a proposed HCWebQ framework interpreted as follows which is called merit value of the responses [36]. In WEBUSE analysis method questions are grouped in such a way that, which quality characteristics they are intended to address. WEBUSE analysis method was selected as the best analysis method when researchers are using Likert scale questions for data collection in usability evaluation of websites[36][35]. The WEBUSE analysis was adopted from the previous works on this study[36]. The merit value of high-level quality characteristics calculated as follows:

\section{$X=\frac{\sum \quad \text { Merit point of each question of the quality metrics }}{\text { Total number of questions for the quality metrics }}$}

Finally, the overall quality of the website high-level characteristics calculated and interpreted as follows:
$Q=\sum_{i=0}^{n} \mathrm{Xi} / \mathbf{n}$

Where

$\mathrm{X}$ is the average merit point of high level quality characteristics

$\mathrm{Q}$ is the mean average of the overall quality of the website $\mathrm{n}$ is the total number of items in the questionnaire

The average merit points of high-level quality characteristics and sub-characteristics, as well as metrics in WEBUSE analysis method, are starts from 0 up to 1 with their interpretation of the overall website quality level [2][35][36]. The interpretations for the WEBUSE analysis tool is shown in Table I which tells the level of quality of the evaluated website[2][36].

Table- I: Point intervals and overall quality levels

\begin{tabular}{|l|c|c|l|c|l|}
\hline $\begin{array}{l}\text { Merit } \\
\text { points, } \boldsymbol{X}\end{array}$ & $\begin{array}{c}0<=\mathrm{x}<= \\
0.2\end{array}$ & $\begin{array}{c}0.2<\mathrm{x}<= \\
0.4\end{array}$ & $\begin{array}{c}0.4<\mathrm{x}<= \\
0.6\end{array}$ & $\begin{array}{c}0.6<\mathrm{x}<= \\
0.8\end{array}$ & $\begin{array}{c}0.8<\mathrm{x}<= \\
1.0\end{array}$ \\
\hline $\begin{array}{l}\text { Overall } \\
\text { quality level } \\
\text { of website }\end{array}$ & $\mathrm{Bad}$ & Poor & $\begin{array}{l}\text { Moderat } \\
\mathrm{e}\end{array}$ & Good & $\begin{array}{l}\text { Excellen } \\
\mathrm{t}\end{array}$ \\
\hline
\end{tabular}

The Kadisco general hospital (KGH), St. Paul's hospital millennium medical college(SPHMMC), Wudassie diagnostic center(WDC) websites are selected for the case study based on the objective, which was aimed to develop website quality evaluation framework in a perspective of the end-user or patients.

\section{B. Data collection and analysis}

To gather data from the end-user of Ethiopian healthcare website, questionnaires were derived from the metrics of the HCWebQ framework. HCWebQ framework applied to the Kadisco general hospital, St. Paul's hospital millennium medical college, Wudassie diagnostic center websites as a case study using a questionnaire and analysis is done on the responses of patients or users. Firstly, responses of the end-user or patients are collected and converted to R software and excel software[34]. Secondly, the internal consistency(Reliability) of responses are analyzed whether the data can be used for further analysis or not using statistical analysis method called Cronbach's alpha[2][35][37]. The intervals of Cronbach's alpha used for analysis are discussed above. Thirdly, using WEBUSE analysis method the gathered data on case study websites was calculated[36]. Finally, the perception of patients on overall quality of case study websites gathered by a single question in a questionnaire compared with the result of WEBUSE analysis and the result are discussed[36].

\section{GENERATING THE HCWEBQ FRAMEWORK}

In Ethiopia, the use of the healthcare website has no difference when compared with the international one. The main participants of Ethiopian healthcare websites are: Patients, Health professionals, Healthcare provider or owners, Managers, Health students, Researchers The HCWebQ framework is built based on ISO/IEC 25010 prescribed characteristics and sub-characteristics considering 
patients as the end-user of the website [28][9]. The HCWebQ framework contains six quality characteristics, thirty one sub-characteristics and quality indicators or metrics for each sub-characteristics [29][10]. Domain specific functionality changed for website evaluation based on the domain of the website to be evaluated [29]. The hierarchical representation of HCWebQ framework is given in the Fig. 2, which intended to simplify the understandability of the framework. The HCWebQ framework uses bottom up approach for calculation of the overall quality of Ethiopian healthcare website quality selected for evaluation. Quality metrics or indicators defined are used to calculate the level of quality of each sub-characteristics of the website. The summation of the level of quality of each sub-characteristics grouped under the same high-level characteristics is used to obtain the quality of high-level characteristics of the website. Finally, the summation of the value obtained for each high-level characteristics result in the overall quality of healthcare website quality selected for evaluation.

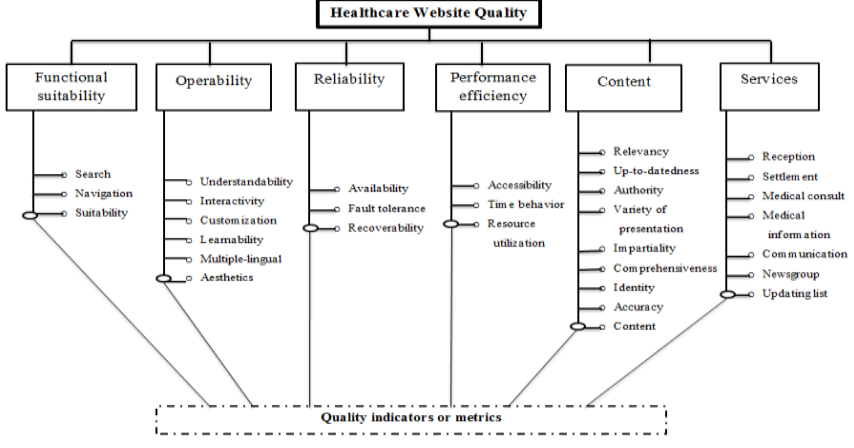

Fig. 2.The proposed quality evaluation framework for the Ethiopian healthcare website

\section{ANALYSIS OF THE HCWEBQ FRAMEWORK}

This section discusses the analysis of the HCWebQ framework and evaluates the level of quality the websites those are selected for a case study. The HCWebQ framework is tested by applying it as a case study to the selected website and analyzing of its reliability. The questions were designed and grouped under which quality characteristics and sub-characteristics they are intended to address. The detail steps discussed in section 3 is used to generate the questions. In addition to the questions, the HCWebQ framework comprehensiveness also showed by comparing the available software quality evaluation model in healthcare website quality evaluation. The questionnaires derived from the HCWebQ framework are applied to the case study websites. The Table II Compares the HCWebQ framework with ISO/IEC 25010 model.

Table- II: Comparison of the HCWebQ framework with ISO/IEC 25010 model

\begin{tabular}{|c|c|c|l|l|}
\hline $\begin{array}{c}\text { Character } \\
\text { istics }\end{array}$ & $\begin{array}{c}\text { Sub-character } \\
\text { istics }\end{array}$ & $\begin{array}{l}\text { ISO/I } \\
\text { EC } \\
\mathbf{2 5 0 1} \\
\mathbf{0 - 1}\end{array}$ & $\begin{array}{l}\text { HCWeb } \\
\mathbf{Q} \\
\text { Framew } \\
\text { ork }\end{array}$ & $\begin{array}{l}\text { Questions to } \\
\text { address the } \\
\text { metrics }\end{array}$ \\
\hline & Search & & Y & 1,2 \\
\hline
\end{tabular}

\begin{tabular}{|c|c|c|c|c|}
\hline \multirow{2}{*}{$\begin{array}{l}\text { Functional } \\
\text { suitability }\end{array}$} & Navigation & & $\mathrm{Y}$ & $3,4,5,6,7,8$ \\
\hline & Suitability & $\mathrm{Y}$ & $\mathrm{Y}$ & 9 \\
\hline \multirow{6}{*}{ Operability } & $\begin{array}{l}\text { Understandabil } \\
\text { ity }\end{array}$ & $\mathrm{Y}$ & $\mathrm{Y}$ & 10,11 \\
\hline & Interactivity & & $\mathrm{Y}$ & 12 \\
\hline & Customization & & $\mathrm{Y}$ & 13 \\
\hline & Learnability & $\mathrm{Y}$ & $\mathrm{Y}$ & 14 \\
\hline & $\begin{array}{l}\text { Multiple-lingua } \\
1\end{array}$ & & $\mathrm{Y}$ & 15,16 \\
\hline & Aesthetics & & $\mathrm{Y}$ & 17 \\
\hline \multirow{3}{*}{ Reliability } & Availability & $\mathrm{Y}$ & $\mathrm{Y}$ & 18 \\
\hline & Fault tolerance & $\mathrm{Y}$ & $\mathrm{Y}$ & 19 \\
\hline & Recoverability & $\mathrm{Y}$ & $\mathrm{Y}$ & 20 \\
\hline \multirow{3}{*}{$\begin{array}{l}\text { Performanc } \\
\text { e efficiency }\end{array}$} & Accessibility & $\mathrm{Y}$ & $\mathrm{Y}$ & $21,22,23,24$ \\
\hline & Time behavior & $\mathrm{Y}$ & $\mathrm{Y}$ & 25,26 \\
\hline & $\begin{array}{l}\text { Resource } \\
\text { utilization }\end{array}$ & $\mathrm{Y}$ & $\mathrm{Y}$ & 27 \\
\hline \multirow[t]{9}{*}{ Content } & Relevancy & & $\mathrm{Y}$ & 28 \\
\hline & $\begin{array}{l}\text { Up-to-datednes } \\
\mathrm{s}\end{array}$ & & $\mathrm{Y}$ & 29,30 \\
\hline & Authority & & $\mathrm{Y}$ & 31,32 \\
\hline & $\begin{array}{l}\text { Variety of } \\
\text { presentation }\end{array}$ & & $\mathrm{Y}$ & 33 \\
\hline & Impartiality & & $\mathrm{Y}$ & 34 \\
\hline & $\begin{array}{l}\text { Comprehensive } \\
\text { ness }\end{array}$ & & $\mathrm{Y}$ & 35 \\
\hline & Identity & & $\mathrm{Y}$ & 36,37 \\
\hline & Accuracy & & $\mathrm{Y}$ & 38,39 \\
\hline & Contact & & $\mathrm{Y}$ & 40 \\
\hline \multirow{7}{*}{ Service } & Reception & & $\mathrm{Y}$ & 41,42 \\
\hline & Settlement & & $\mathrm{Y}$ & 43 \\
\hline & Medical consult & & $\mathrm{Y}$ & 44,45 \\
\hline & $\begin{array}{l}\text { Medical } \\
\text { information }\end{array}$ & & $\mathrm{Y}$ & $46,47,48$ \\
\hline & $\begin{array}{l}\text { Communicatio } \\
\mathrm{n}\end{array}$ & & $\mathrm{Y}$ & 49 \\
\hline & Newsgroup & & $\mathrm{Y}$ & 50,51 \\
\hline & Updating list & & $\mathrm{Y}$ & 52,53 \\
\hline
\end{tabular}

Data collected from the end-user with questionnaire. Among the intended 210 participants to evaluate three Ethiopian hospital websites as experimental websites selected, only 140 respondents evaluated the case study website with valid data. Others didn't provide demographic information's correctly, and others refused the evaluation. 64 respondents evaluated Kadisco general hospital website with valid data, 34 respondents evaluated St. Paul's hospital millennium medical college with valid data and 42 respondents' evaluated Wudassie diagnostic center website with designed data. The respondents outcome are discarded from the data if the respondents not aware of any hospital website in Ethiopia, having the concept that if evaluators at least know the healthcare website, they may know what information and services are expected from the health-related websites. Totally 140 respondents response on three selected case study website and their responses considered for analysis and validation of tools as well as to identify the level of quality of each website from the end-user perspectives. The summary of 


\section{Quality Examination Framework for Ethiopian Healthcare Websites}

demographic information of the respondents those participated in the evaluation of the three case study website was summarized as in Fig.3, Fig.4, Fig.5.

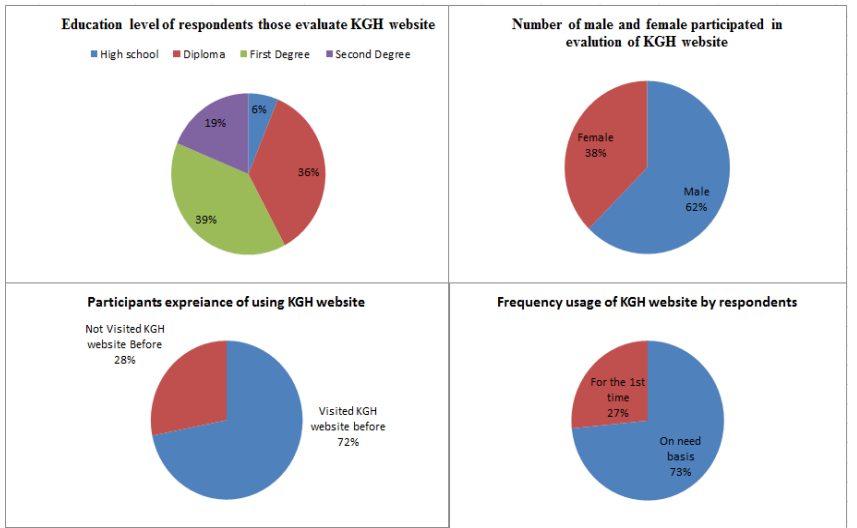

Fig. 3.KGH evaluator's demographic information

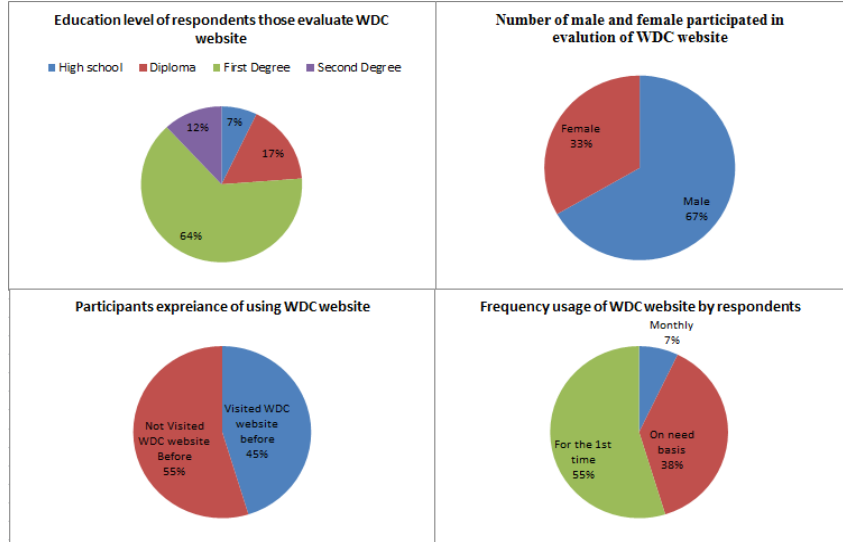

Fig. 4.WDC evaluator's demographic information

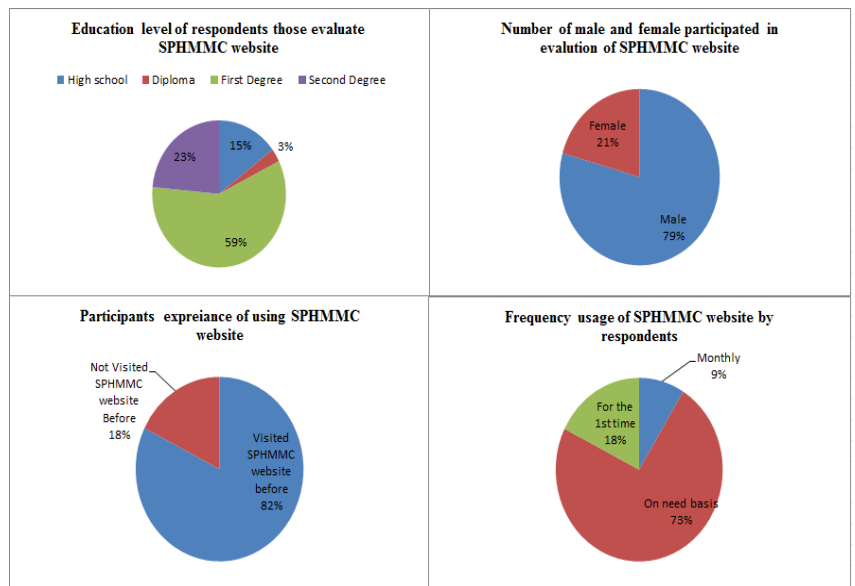

Fig. 5.SPHMMC evaluator's demographic information

The reliability of items (questions in a questionnaire) in a proposed framework analyzed using Cronbach's alpha and item-total correlation. Cronbach's alpha and item-total correlation is to the internal consistency of the questions used in a questionnaire. The rule-of-thumb of the Cronbach's alpha says the internal consistency is high in the items if the value of Cronbach's alpha is greater or equal to 7[34]. The item-total correlation in a tool should be positive, and if item negatively correlates to the total item in a tool, there should be a need to modify the item or remove the item[2]. The HCWebQ framework internal consistency was intended to be proved by applying the framework to existing hospital websites and the reliability of the tool is measured.

The HCWebQ framework applied to $\mathrm{KGH}$, WDC, and SPHMMC healthcare websites in the form of a questionnaire. The questionnaires prepared from the metrics in the HCWebQ framework are used to gather the level of agreement of users as a patient on the hospital's website. Many researchers in the area followed the same way which is utilized in preparing the questionnaire for validating the HCWebQ framework [1][4][2][33]. The reliability of the HCWebQ framework is discussed in the next section which was interpreted from the output of R software and Microsoft Excel. The Q1, Q2, Q3, Q4... Q53 in the data analysis part was used to represent 53 questions in a questionnaire, those used to collect data. The short form used to represent the longest question in the data analysis.

Table- III: Total Cronbach's alpha value of the proposed framework

\begin{tabular}{|l|c|c|c|}
\hline Websites & $\begin{array}{l}\text { KGH } \\
\text { website }\end{array}$ & $\begin{array}{l}\text { WDC } \\
\text { website }\end{array}$ & $\begin{array}{l}\text { SPHMMC } \\
\text { website }\end{array}$ \\
\hline Alpha reliability & $\mathbf{0 . 9 4 1 2}$ & $\mathbf{0 . 9 3 7 8}$ & $\mathbf{0 . 7 7 9 5}$ \\
\hline $\begin{array}{l}\text { No. of items } \\
\text { (Questions) }\end{array}$ & $\mathbf{5 3}$ & $\mathbf{5 3}$ & $\mathbf{5 3}$ \\
\hline
\end{tabular}

The value of the Cronbach's alpha in the Table III shows the HCWebQ framework applied to a three Ethiopian healthcare website and its reliability were in the interval of Excellent (on $\mathrm{KGH}$ website and WDC website) and Acceptable on the SPHMMC website. The value of Cronbach's alpha greater than 0.7 , it means the acceptable internal consistency. If items in the framework have above acceptable internal consistency then the framework proved valid and can be used in different websites evaluation in healthcare websites. The alpha reliability if items deleted indicates the value of Cronbach's alpha if that particular question removed from the framework. If alpha reliability after items is deleted greater when item exists, it can be possible to remove the item from the framework [2]. The result of scale reliability of items for the new quality metrics in HCWebQ framework, applied to three Ethiopian healthcare websites are given in the Table IV.

In the following section the description for the new quality metrics in the HCWebQ framework discussed in terms of the alpha reliability and item-total correlation within the components of the framework. In the HCWebQ framework the new sub-characteristics added under functional suitability are search and navigation. In the framework Q1 and Q2 were included to measure the search sub-characteristics. The alpha reliability of Q1 and Q2 after question (item) deleted was increased in $\mathrm{KGH}$ website (0.9424 and 0.9438 respectively), less in WDC website (0.9348 and 0.9344 respectively) and greater in SPHMMC website greater for Q1 (0.7854) but less for Q2 (0.7823). The item-total correlation was negative for both question in $\mathrm{KGH}$ (-0.0396 and -0.3959 respectively), positive for both question

in WDC $(0.6996$ and 0.7763 respectively) and negative 
for Q1 (-0.2436) but positive for Q2 (0.0399) in SPHMMC website. Therefore, the question used to address the sub-characteristics need modification.

Table- IV: Scale reliability for new quality metrics in the HCWebQ framework

\begin{tabular}{|c|c|c|c|c|c|c|}
\hline \multicolumn{7}{|c|}{ Reliability deleting each item in turn: } \\
\hline \multirow[b]{2}{*}{ Items } & \multicolumn{2}{|c|}{ KGH website } & \multicolumn{2}{|c|}{ WDC website } & \multicolumn{2}{|c|}{ SPHMMC website } \\
\hline & Alpha & r(item, total) & Alpha & r(item, total) & Alpha & r(item, total) \\
\hline Q.1 & 0.9424 & -0.0396 & 0.9348 & 0.6996 & 0.7854 & -0.2436 \\
\hline Q.2 & 0.9438 & -0.3959 & 0.9344 & 0.7763 & 0.7823 & 0.0399 \\
\hline Q.3 & 0.9363 & 0.9194 & 0.9352 & 0.7352 & 0.7714 & 0.3714 \\
\hline Q.4 & 0.9376 & 0.8053 & 0.9372 & 0.3743 & 0.7652 & 0.5718 \\
\hline Q.5 & 0.9366 & 0.9336 & 0.9368 & 0.4675 & 0.7825 & -0.0780 \\
\hline Q.6 & 0.9389 & 0.6995 & 0.9361 & 0.5494 & 0.7686 & 0.6013 \\
\hline Q.7 & 0.9363 & 0.9206 & 0.9363 & 0.5648 & 0.7674 & 0.5583 \\
\hline Q.8 & 0.9372 & 0.8238 & 0.9347 & 0.8348 & 0.7747 & 0.3050 \\
\hline Q.12 & 0.9471 & -0.5660 & 0.9357 & 0.6105 & 0.7723 & 0.3341 \\
\hline Q.13 & 0.9434 & -0.3526 & 0.9378 & 0.2395 & 0.7761 & 0.2258 \\
\hline Q.15 & 0.9425 & -0.0666 & 0.9370 & 0.4117 & 0.7646 & 0.6683 \\
\hline Q.16 & 0.9426 & -0.0878 & 0.9403 & -0.0193 & 0.7835 & -0.0729 \\
\hline Q.17 & 0.9382 & 0.7650 & 0.9405 & 0.0062 & 0.7760 & 0.2282 \\
\hline Q.28 & 0.9379 & 0.8674 & 0.9368 & 0.4536 & 0.7761 & 0.2590 \\
\hline Q.29 & 0.9424 & -0.0595 & 0.9366 & 0.4793 & 0.7703 & 0.4021 \\
\hline Q.30 & 0.9394 & 0.7977 & 0.9375 & 0.3698 & 0.7722 & 0.3260 \\
\hline Q.31 & 0.9426 & -0.0878 & 0.9378 & 0.2915 & 0.7673 & 0.4174 \\
\hline Q.32 & 0.9427 & -0.1506 & 0.9361 & 0.5406 & 0.7729 & 0.3071 \\
\hline Q.33 & 0.9394 & 0.7977 & 0.9374 & 0.3715 & 0.7785 & 0.1486 \\
\hline Q.34 & 0.9414 & 0.3019 & 0.9367 & 0.4792 & 0.7864 & -0.0322 \\
\hline Q.35 & 0.9378 & 0.8673 & 0.9358 & 0.7139 & 0.7712 & 0.4804 \\
\hline Q.36 & 0.9372 & 0.8397 & 0.9362 & 0.6488 & 0.7841 & -0.0516 \\
\hline Q.37 & 0.9388 & 0.6785 & 0.9362 & 0.5345 & 0.7668 & 0.4783 \\
\hline Q.38 & 0.9401 & 0.4726 & 0.9344 & 0.7482 & 0.7675 & 0.4660 \\
\hline Q.39 & 0.9419 & 0.1491 & 0.9365 & 0.4817 & 0.7794 & 0.1328 \\
\hline Q.40 & 0.9405 & 0.3895 & 0.9426 & -0.3820 & 0.7727 & 0.3373 \\
\hline Q.41 & 0.9383 & 0.7731 & 0.9361 & 0.5406 & 0.7693 & 0.5764 \\
\hline Q.42 & 0.9374 & 0.8342 & 0.9365 & 0.5217 & 0.7796 & 0.0636 \\
\hline Q.43 & 0.9457 & -0.3556 & 0.9354 & 0.6319 & 0.7716 & 0.3964 \\
\hline Q.44 & 0.9412 & 0.2390 & 0.9385 & -0.0301 & 0.7817 & 0.0205 \\
\hline Q.45 & 0.9375 & 0.8698 & 0.9356 & 0.6108 & 0.7771 & 0.1929 \\
\hline Q.46 & 0.9384 & 0.7401 & 0.9396 & 0.0184 & 0.7667 & 0.4834 \\
\hline Q.47 & 0.9410 & 0.2739 & 0.9359 & 0.6075 & 0.7885 & -0.2656 \\
\hline Q.48 & 0.9408 & 0.3315 & 0.9367 & 0.4696 & 0.7881 & -0.1696 \\
\hline Q.49 & 0.9400 & 0.5232 & 0.9376 & 0.3294 & 0.7818 & 0.1053 \\
\hline Q.50 & 0.9393 & 0.7127 & 0.9363 & 0.5382 & 0.7932 & -0.2916 \\
\hline Q.51 & 0.9426 & -0.1084 & 0.9380 & 0.2501 & 0.7881 & -0.0919 \\
\hline Q.52 & 0.9397 & 0.7527 & 0.9335 & 0.9142 & 0.7970 & -0.3202 \\
\hline Q.53 & 0.9410 & 0.3038 & 0.9394 & 0.0057 & 0.7914 & -0.2870 \\
\hline
\end{tabular}

In the HCWebQ framework, Q1 through Q8 were included to measure the navigation sub-characteristic. The alpha reliability and item-total correlation of all question designed to address navigation sub-characteristic were internally consistent with all items in the HCWebQ framework, but on question Q5 alpha reliability increased and had a negative item-total correlation. Therefore, question Q5 need more clarification to make it more usable. The sub-characteristics added under operability in the framework were interactivity, customization, multi-lingual, and aesthetics those are not addressed in ISO 25010 quality evaluation models. In the HCWebQ framework Q12 were added to measure the interactivity sub-characteristic of the websites. The alpha reliability of the question 12 after Q12 deleted increased in $\mathrm{KGH}$ website (0.9471), as well as its item-total correlation, was -0.5660 but in both WDC and SPHMMC website, the question's internal consistency was good. In the HCWebQ framework Q13 was added to measure the customization sub-characteristic of the websites. The alpha reliability of the question 13 after Q13 deleted increased in $\mathrm{KGH}$ website (0.9471), as well as its item-total correlation, was -0.5660 but in both WDC and SPHMMC website, the question's internal consistency was good. In the HCWebQ framework Q15 and Q16 were added to measure the Multi-lingual sub-characteristic of the websites. The alpha reliability of the question 15 after Q15 deleted; increased in $\mathrm{KGH}$ website $(0.9425)$ as well as its item-total correlation was -0.0666 but in both WDC and SPHMMC website the question's internal consistency 15 was good. The internal consistency of Q15 in both WDC and SPHMMC websites was good.

Table- V: Alpha reliability and item-total correlation for Q16

\begin{tabular}{|l|l|l|l|l|l|l|}
\hline \multicolumn{7}{|c|}{ Reliability deleting each item in turn } \\
\hline \multirow{2}{*}{$\begin{array}{l}\text { Ite } \\
\text { ms }\end{array}$} & \multicolumn{2}{|c|}{ KGH website } & \multicolumn{2}{c|}{ WDC website } & \multicolumn{2}{c|}{ SPHMMC website } \\
\cline { 2 - 7 } & Alpha & $\begin{array}{l}\mathrm{r} \text { (item, } \\
\text { total) }\end{array}$ & Alpha & $\begin{array}{l}\mathrm{r} \text { (item, } \\
\text { total) }\end{array}$ & Alpha & $\begin{array}{l}\mathrm{r} \text { (item, } \\
\text { total) }\end{array}$ \\
\hline $\mathrm{Q} .1$ & 0.942 & -0.0878 & 0.940 & -0.0193 & 0.783 & -0.0729 \\
6 & 6 & & 3 & & 5 & \\
\hline
\end{tabular}

The Table V shows that question 16 in the HCWebQ framework was internally not consistent in three websites evaluated in a case study. The alpha reliability after question 16 removed was greater than the scale reliability and the question was negatively correlated with the total added item in the framework. Therefore, it should be either reframed or removed from the tool.

\section{A. WEBUSE - A Case Study Analysis}

The WEBUSE analysis tool was used to analyze the quality of the three case study websites. The WEBUSE analysis method was used, and its reliability was proved by different works in website quality evaluation as well as website usability evaluation [2][35]. Therefore, depending on the metrics for WEBUSE tool the responses of evaluators for three case study websites of Ethiopian healthcare analyzed as follows. The availability, recoverability and fault-tolerance sub-characteristics are included under the reliability dimension of the framework. The results of the study showed that the availability of $\mathrm{KGH}$ website was good and others are fair and the fault tolerance of $\mathrm{KGH}$ website was good and others are fair. Further the result showed that recoverability of SPHMMC website was moderate and others are fair. The accessibility, time behavior, and resource utilization sub-characteristics are included under the reliability dimension of the framework. It's visible from the result, that the accessibility of $\mathrm{KGH}$ was moderate for respondents whereas time behavior was good and resource utilization was fair level.

The service characteristics were included in the study to address facilities exist on the website for healthcare providers to serve their patients user online using the website. The qualities of online reception on all websites are below the moderate level. In a summarized form the result of the case study on the service characteristics showed that all sub-characteristics included under service characteristics are implemented in all case study websites below the moderate level of website quality. Therefore, for developer or owner, there is need to focus on this characteristic. The final results of WEBUSE analysis for the six characteristics are included in the HCWebQ framework of three case study websites is given in Table VI. 
Quality Examination Framework for Ethiopian Healthcare Websites

Table- VI: WEBUSE analysis result for all sub-characteristics

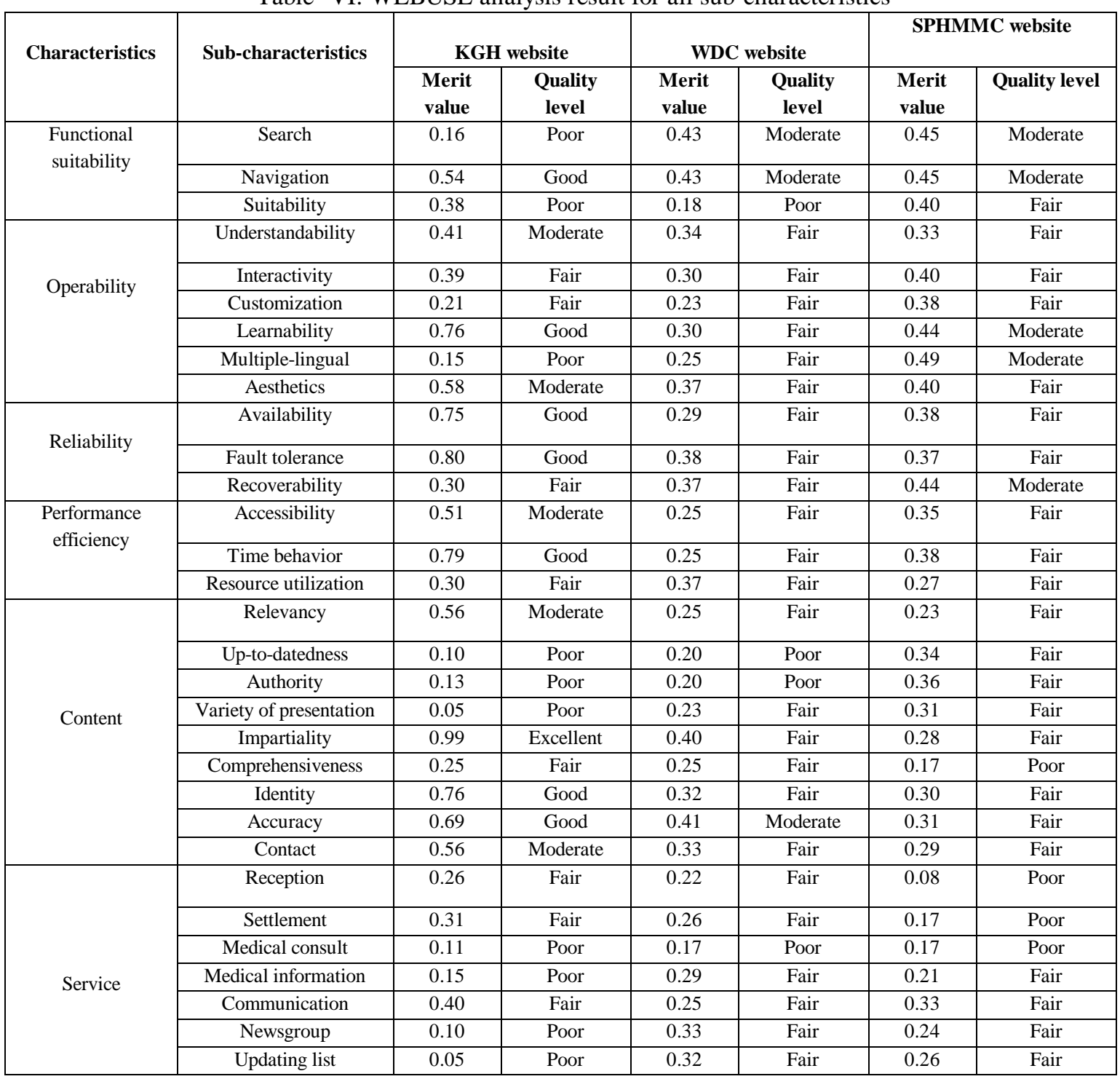

Table- VII: WEBUSE analysis result for all characteristics

\begin{tabular}{|l|l|l|l|l|l|l|}
\hline \multirow{2}{*}{$\begin{array}{l}\text { High-level } \\
\text { characteristics }\end{array}$} & \multicolumn{3}{|c|}{ KGH website } & \multicolumn{2}{c|}{ WDC website } & \multicolumn{2}{c|}{$\begin{array}{l}\text { SPHMMC } \\
\text { website }\end{array}$} \\
\cline { 2 - 7 } & $\begin{array}{l}\text { Merit } \\
\text { value }\end{array}$ & $\begin{array}{l}\text { Quality } \\
\text { level }\end{array}$ & $\begin{array}{l}\text { Merit } \\
\text { value }\end{array}$ & $\begin{array}{l}\text { Quality } \\
\text { level }\end{array}$ & $\begin{array}{l}\text { Merit } \\
\text { value }\end{array}$ & $\begin{array}{l}\text { Quality } \\
\text { level }\end{array}$ \\
\hline $\begin{array}{l}\text { Functional } \\
\text { suitability }\end{array}$ & 0.36 & Fair & 0.35 & Fair & 0.43 & Moderate \\
\hline Operability & 0.42 & Moderate & 0.30 & Fair & 0.41 & Moderate \\
\hline Reliability & 0.62 & Good & 0.35 & Fair & 0.40 & Fair \\
\hline $\begin{array}{l}\text { Performance } \\
\text { efficiency }\end{array}$ & 0.53 & Moderate & 0.29 & Fair & 0.33 & Fair \\
\hline Content & 0.45 & Moderate & 0.29 & Fair & 0.29 & Fair \\
\hline Service & 0.20 & Poor & 0.26 & Fair & 0.21 & Fair \\
\hline Average & $\mathbf{0 . 4 3}$ & Moderate & $\mathbf{0 . 3 1}$ & Fair & $\mathbf{0 . 3 5}$ & Fair \\
\hline
\end{tabular}

The Table VII and Fig. 6 represent the result of case study website in simplified and variety of formats. As it is possible to understand from the result, to improve the website quality in Ethiopia it needs a great job for developers and owners with great responsibility. The quality any websites in any domain are advised as if its quality be at least in a good interval to satisfy the users. Generally, the WEBUSE analysis showed great improvement required for all characteristics of a website considered in the HCWebQ framework. The average result of the Table VII shows the overall quality of the websites, which is the quality level of the $\mathrm{KGH}$ website is moderate, WDC is fair, and SPHMMC website is also fair. 


\title{
Overall quality of case study website, result of WEBUSE analsis
}

\author{
KGH website WDC website SPHMMC website
}

1

0.8

0.6

Quality level

0.4

0.2

0

Functional Operability Reliability Performance Content Serv

Fig. 6.Overall result of WEBUSE analysis method

Fig. 6 shows that the levels of quality of functional suitability of SPHMMC website are greater than KGH and WDC websites. The level of quality of operability of $\mathrm{KGH}$ website is greater than WDC and SPHMMC websites, the level of quality of reliability of $\mathrm{KGH}$ website greater than WDC and SPHMMC websites, the level of quality of performance efficiency of $\mathrm{KGH}$ website were greater than WDC and SPHMMC websites, the level of quality of content of $\mathrm{KGH}$ website were greater than WDC and SPHMMC websites and the level of quality of service of WDC website were greater than $\mathrm{KGH}$ and SPHMMC websites.

To gather the overall perception or level of quality of website, an additional one question was added to the questionnaire which has a similar format with other questions in a questionnaire distributed to respondents. The question was asking evaluators to forward their feeling on the overall quality of the website without specifying characteristics and sub-characteristics. The question contained five options. Those are: Bad [0-0.2], Poor (0.2-0.4], Good (0.4-0.6], Very good (0.6-0.8] and Excellent $(0.8-1.0]$. The value of bad, poor, good, very good and excellent used for perception gathering matched to poor, fair, moderate, good and excellent are in WEBUSE analysis method. Table VIII shows the single question added in a questionnaire to gather perception of the evaluators on the three case study website.

Table VIII shows that the overall rating of respondents was $43.75 \%$ moderate, $29.69 \%$ poor, $15.63 \%$ fair, $10.94 \%$ good and none of them rated with an excellent quality level in $\mathrm{KGH}$ website. The respondents rating for WDC website was $35.71 \%$ fair, $28.57 \%$ poor, $26.19 \%$ moderate, $9.52 \%$ good and none of them rated it with excellent. The respondents rating for SPHMMC website was $41.18 \%$ fair, $35.29 \%$ poor, $23.53 \%$ good and none of them rated it with moderate and excellent.

Table VIII: Response rate on perception gathering

\begin{tabular}{|c|c|c|c|c|c|c|}
\hline \multirow{2}{*}{$\begin{array}{c}\text { Quality } \\
\text { level }\end{array}$} & \multicolumn{2}{|c|}{ KGH website } & \multicolumn{2}{c|}{ WDC website } & \multicolumn{2}{c|}{ SPHMMC website } \\
\cline { 2 - 7 } & $\boldsymbol{N}^{*}=\mathbf{6 4}$ & Percent & $\boldsymbol{N}^{*}=\mathbf{4 2}$ & Percent & $\boldsymbol{N}^{*}=\mathbf{3 4}$ & Percent \\
\hline Poor & 19 & 29.69 & 12 & 28.57 & 12 & 35.29 \\
\hline Fair & 10 & 15.63 & 15 & 35.71 & 14 & 41.18 \\
\hline Moderate & 28 & 43.75 & 11 & 26.19 & 0 & 0.00 \\
\hline Good & 7 & 10.94 & 4 & 9.52 & 8 & 23.53 \\
\hline Excellent & 0 & 0.00 & 0 & 0.00 & 0 & 0.00 \\
\hline
\end{tabular}




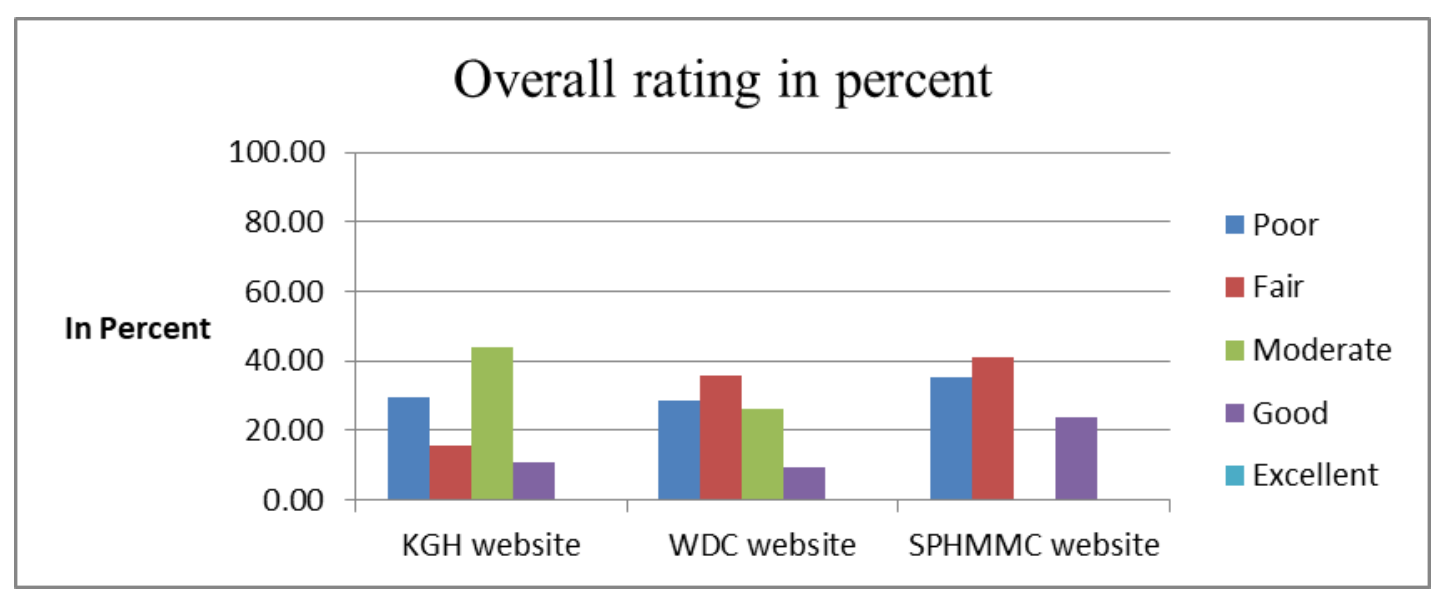

Fig. 7.Overall rating of respondents

The Fig. 7. shows the overall rating of respondents. The Fig. 7. shows that the overall rating of respondents was for KGH website moderate and both WDC and SPHMMC websites fair. No one rate the SPHMMC website with moderate.

The results of WEBUSE analysis and respondents perception are similar. The result of WEBUSE analysis was moderate for $\mathrm{KGH}$ website and fair for both WDC and SPHMMC websites. Similarly, greatest percent of respondents rated $\mathrm{KGH}$ website with moderate and rated with fair both WDC and SPHMMC websites. Therefore, the quality evaluation framework proposed for the Ethiopian healthcare website gives a reliable result that similar to respondents' perception. This means the framework represents patients' or end-users' perception for evaluating the quality of the healthcare website. This shows the HCWebQ framework has components to evaluate healthcare website that an end-user expected from the website of healthcare. The result showed the proposed framework was more comprehensive than the ISO/IEC 25010 quality evaluation model.

\section{CONCLUSION AND FUTURE WORK}

The study revealed that existing website quality models, frameworks and standards are not considered comprehensive characteristics used to evaluate healthcare websites. Besides, they did not consider the perspectives of patients', users and their relevant characteristics. The HCWebQ framework was intended to represent end-users perceptions on healthcare website, and it was as it intended. Even though, the developed solution enables to improve the quality of website from end-users perspectives the following works should be carried out in the future. The weighting of characteristics, sub-characteristics and metrics are another open issue in the HCWebQ framework and needs further research.

\section{REFERENCES}

1. Rajesh Kumar and Santosh Rangnekar, "Measuring Website Quality of the Indian Railways," International Journal of Entrepreneurial Knowledge, vol. 3 , no. 1,2015

2. T. Mebrate, "A framework for evaluating Academic Website's quality," TUDelft, The Netherlands, Netherland, 2010.

3. Salam Abdallah and Bushra Jaleel, "Website Appeal: Development of an Assessment Tool and Evaluation Framework of E-Marketing," Journal of

Theoretical and Applied Electronic Commerce Research, vol.10, no. 3, pp. 45-47, September 2015.

4. Kalpana Devi and Aman Kumar Sharma, "Implementation of a Framework for Website Quality Evaluation: Himachal Pradesh University Website," Indian Journal of Science and Technology, Vol 9, no. 40, pp. 1-4, October 2016

5. O. Signore, "Towards a Quality Model for Web Sites," in CMG Poland Annual Conference, Italy, May 2005

6. Muhammad Saeed and Sami Ullah, "Usability Evaluation of a Health Web Portal," Blekinge Institute of Technology, Sweden, June 2009.

7. Álvaro Rocha, Avelino Victor, Patrícia Leite Brandão, "Quality of Health Web Sites: Dimensions for a Wide Evaluation," Springer, Verlag Berlin Heidelberg, 2011.

8. Luisa Mich, Mariangela Franch, and Loris Gaio "Evaluating and Designing website quality," IEEE Computer Society, pp. 34-38, 2009.

9. José P. Miguel, David Mauricio, Glen Rodríguez"A Review of Software Quality Models for the Evaluation of Software Products," International Journal of Software Engineering Applications (IJSEA), vol.5, no. 6, pp. 31-45, November 2014

10. Motoei Azuma, "ISO/IEC CD 25010, Software product Quality Requirements and Evaluation, Software and quality in use models," Canada, 2008.

11. Álvaro Rocham, "Framework for a global quality evaluation of a website", Online Information Review, vol. 36, no. 3, pp. 374-382, 2012.

12. Fatemeh Rangraz Jeddi, Hamidreza Gilasi, and Sahar Khademi., "Evaluation models and criteria of the quality of hospital websites: a systematic review study," Electronic Physician, vol. 9, no. 2, pp. 3786-3793, February 2017.

13. A. S. Genc, "Web Site Evaluation," Middle East Technical University, 2006.

14. M. A. Asemahagn, "Challenges of ICTs Utilization among Health Professionals: The Case of Public Hospitals in Addis Ababa, Ethiopia," SM Journal of Public Health and Epidemiology, vol. 1(3), no. 1012, pp. 1-2, Sep $04,2015$.

15. B. Liburne, P. Devkota and K. M. Khan, "Measuring Quality Metrics for Web Applications," IRMA International Conference, 2004.

16. Mayte Herrera et al., "Quality in Use Model for Web Portals (QiUWeP)," University of Castilla, La Mancha, 2009.

17. Salarvand, Samadbeik, Tarrahi, Salarvand, "Quality of Public Hospitals Websites: A Cross-Sectional Analytical Study in Iran," Acta Inform Med, vol. 24, no. 2, pp. 130-133, 2016

18. Z. Zhou, "Evaluating Websites using a practical quality model," De Montfort University, 2009

19. Anusha and N. Rama, "A Novel Website Quality and Usability Evaluation Framework for Online Shopping Websites," Indian Journal of Science and Technology, vol. 9(36), pp. 1-6, September 2016.

20. Mark A. Levin Ted T. Kalal Jonathan Rodin, "Applying Software Quality Procedures", Chapter 23, Improving Product Reliability and Software Quality: Strategies, Tools, Process and Implementation, Second Edition, https://doi.org/10.1002/9781119179429.ch23, April 2019

21. Giraldo, F.D., España, S., Pastor, Ó., Giraldo W. J.,"Considerations about quality in model-driven engineering - Current state and challenges", Software Quality Journal, June 2018, Vol. 26, Issue 2, pp 685-750.

22. Fotrousi, F., Fricker, S.A. \& Fiedler, M., "The effect of requests for user feedback on Quality of Experience" Software Quality Journal, June 2018, Volume 26, Issue 2, pp 385-415.

23. Vassilis Moustakis, Loukas Tsironis \& Charalampos Litos, "A model of web site quality assessment Quality Management Journal, Taylor \& Francis,

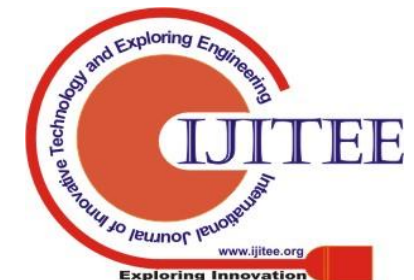


pp. 1068-6967, 2006, doi:10.1080/10686967.2006.11918547

24. D. Gade, "The Evaluation of Sofware Quality," University of Nebraska, Lincoln, 2013.

25. Giraldo, F.D., España, S., Giraldo, W.J., Óscar Pastor.O, Krogstie.J, "A method to evaluate quality of modelling languages based on the Zachman reference taxonomy" Software Quality Journal, Vol. 27, Issue 3, pp 1239-1269, 2019.

26. G. Gledec, "Quality Model for the World Wide Web," 8th International Conference on Telecommunications - ConTEL2005 Zagreb, Croatia, June 2005.

27. W3C, "W3C Quality Assurance," July 2006.

28. S. Wagner, "Quality Models," in Software Product Quality Control, Verlag Berlin Heidelberg, Springer, 2013, pp. 33-34.

29. L. O. Santos, "Measuring web application quality using WebQEM," IEEE Multimedia, pp. 20-25, 2002.

30. K. K. Singh, P. Kumar, "A Model for Website Quality Evaluation - A Practical Approach," International Journal of Research in Engineering \& Technology, vol. 2, no. 3, pp. 61-68, Mar 2014.

31. Ping Zhang, Gisela M. von Dran, Paul Blake, Veerapong Pipithsuksunt, "Important Design Features in Different Web Site Domains," e-Service Journal, pp. 77-91, 2001.

32. O. Signore, "Towards a Quality Model For Web Sites," CMG Poland Annual Conference, May 2005.

33. Rafe V., Monfaredzadeh M., "A Qualitative Framework to Assess Hospital / Medical Websites," Journal of Medical Systems, 36(5), p. 2927-2939, 2011. August

34. http://www.statisticshowto.com/cronbachs-alpha-spss/, 2016.

35. Kalpana Devi, Aman Kumar Sharma, "Evaluating the Quality of Academic Websites using Proposed Framework," International Journal of Computer Trends and Technology (IJCTT), vol. 40, no. 1, pp. 25-30, October 2016.

36. Thiam Kian Chiew and Siti Salwa Salim, "WEBUSE: Website Usability Evaluation Tool," Malaysian Journal of Computer Science, vol. 16, no. 1, pp. 47-57, June 2003

\section{AUTHORS PROFILE}

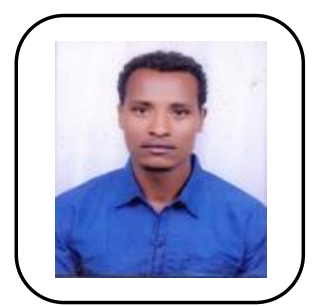

Lami Garoma Abaya is working as Lecturer in Department of Computer Science, Ambo University, Ethiopia. He received his Master of Science in Software Engineering, from Adama Science and Technology University, Adama, Ethiopia. His teaching and research interests includes Software Engineering, Networking, Software Testing. He is currently developing (by adding new features on the existing) Ambo University website, two community service and one research which focuses on solving community problem. He is a Member of scholarship committee at department of computer science Ambo University. He has published papers in various reputed Journals and Conferences.

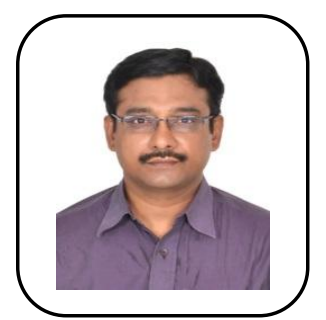

S.Selvakumar received Doctor of Philosophy in Computer Science and Engineering from the Anna University, Chennai and has over 23 years' experience. He has guided over $14 \mathrm{Ph} . \mathrm{D}$. Scholars. Currently he is a Professor, Dept. of CSE, GKM College of Engineering \& Technology, Chennai. He previously worked at Thiagarajar College of Engineering. His teaching and research interests includes Software Engineering, Big data Analytics, Networking. He has published over 130 papers in various SCI \& Scopus Indexed, reputed Journals and Conferences. He is a Senior Member in the Computer Society of India, Member in IEEE, ACM, the Institution of Engineers and the ISTE. He is reviewer in various International journals and IEEE conferences. 